\title{
Safety Impact of Engineering Treatments on Undivided Rural Roads
}

\author{
I. Pérez * \\ Universidade da Coruña. E. T. S. I. Caminos, Campus de Elviña, 15071 A Coruña, Spain
}

\begin{abstract}
This article presents an evaluation of the safety impacts of four engineering treatments implemented in the Autonomous Community of Madrid (Spain): highway upgrading; updating and improvement of traffic signing; repainting of pavement markings and pavement resurfacings. This evaluation was carried out using the Empirical Bayes Method with a comparison group. The functioning of a methodology to test the significance of the safety impact is described. The results show that highway upgrading has a positive and significant safety impact, while the updating and improvement of traffic signing, the repainting of road markings and pavement resurfacings do not exhibit a significant impact on safety.

Keywords: Evaluation, Engineering treatments, Safety impact, Empirical Bayes Method, Significance Test.
\end{abstract}

\section{Introduction}

The evaluation of safety engineering treatments is considered to be a crucial part of highway safety management. The main purpose of evaluation is to estimate the safety impact of engineering treatments. In Spain four engineering treatments are frequently carried out on undivided rural roads: highway upgrading; updating and improvement of traffic signs; repainting of pavement markings and pavement resurfacings. In general, highway upgrading projects are equivalent to those in the USA designated RRR (Resurfacing, Restoration and Rehabilitation) (Transportation Research Board, 1987). According to Cleveland (1987), the safety impacts of RRR projects vary between $21 \%$ and $90 \%$. Also, published results on the safety impacts of traffic signs and pavement markings are variable. For example, according to Llamas (1998), the Federal Highway Administration (FHWA) states that updating and improving traffic signing have a safety impact of $16 \%$, whereas the Transportation Road Laboratory (TRL) reports a figure of $30 \%$. With regard to the safety impact of pavement markings, Al-Masaeid et al (1994) have published several studies carried out for the FHWA where this value fluctuates between $-13 \%$ and $35 \%$. As far as the safety impact of pavement

\footnotetext{
${ }^{*}$ Corresponding author. Tel: (+34) 981.167.000-Ext. 1451. Fax: (+34) 981.167.170. E-mail:iperez@udc.es
} 
resurfacings is concerned, two very different cases can be distinguished. Thus, it has been proven that routine pavement resurfacing on rural roads reduces wet-weather accidents- the number of accidents on wet surfacing diminishes by between $15 \%$ and $70 \%$. In contrast, routine pavement resurfacing on rural roads increases dryweather accidents by about $10 \%$ (Cleveland, 1987).

The objective of this article is to evaluate the safety impacts of these four engineering treatments on undivided rural roads belonging to the highway network of the Autonomous Community of Madrid (ACM), by means of "before and after" studies, using a comparison group. The Empirical Bayesian Method (EBM) was used in conjunction with a statistical procedure which allows the verification of the significance of safety impacts.

\section{Methodology}

\subsection{Estimating the expected number of accidents}

The expected number of accidents $\psi_{i j t}$ (fatal + injury) will be used as an indicator of the safety level of highway locations. It is defined as the mean accident frequency that can be expected to occur at a location $t$ during a period of years, provided that its physical characteristics have not been changed. Researchers have proposed using EBM to predict the expected number of accidents at a location belonging to a highway network (Leotsarakos, 1988; Al-Masaeid, 1990; Hauer, 1997). It has been demonstrated that the estimation of $\psi_{i j t}$ may be expressed as (Abbess et al, 1981):

$$
\psi_{i j t}=\left(\alpha_{i j t}+N_{i j t}\right)\left(\omega_{i j t}+y\right)
$$

where $\alpha_{i j t} \& \omega_{i j t}=$ A priori Gamma type distribution parameters. In each location $t$ the expected number of accidents is dependent on a priori information and recorded data. A priori information may be interpreted as the observation of $\alpha_{i j t}$ accidents in $\omega_{i j t}$ years at location $t$. Recorded data represent $N_{i j t}$ accidents in $y$ years at location $t$. Moreover, the probability of recording a number of accidents $N$ in an aggregate population of similar locations may be modelled by means of a negative binomial distribution. Therefore, the parameters $\alpha_{i j t} \& \omega_{i j t}$ can be estimated by fitting a negative binomial distribution to a sample that includes accidents at locations having the same characteristics as the one under consideration (Maritz and Lwin, 1989). 


\subsection{Evaluation}

Four averages of the expected numbers of accidents $\left(\psi_{i j t}\right)$ are obtained by:

$$
\psi_{i j .}=\sum_{t=1}^{n_{i j}} \psi_{i j t} / n_{i j}
$$

Thus, safety impact $S /(\%)$ is evaluated as a function of these four averages (Council et al, 1980):

$$
S I(\%)=\left[1-\left(\psi_{12} / \psi_{11 .}\right) /\left(\psi_{22} / \psi_{21 .}\right)\right] \cdot 100
$$

where $\psi_{i j}=$ Average of the $\psi_{i j t}$ : in the treatment group (i=1), in the comparison group (i=2); in the "before" period $(j=1)$, in the "after" period $(j=2) . n_{i j}=$ Number of locations.

\subsection{Statistical significance}

A "Two-factor factorial model" (Sahai and Ageel, 2000) is proposed to determine whether or not $S I(\%)$ is significant:

$$
\psi_{i j t}=\mu+v_{i}+\beta_{j}+v \beta_{i j}+\xi_{i j t}
$$

where $\mu=$ constant; $v_{i}=$ the effect on the expected number of accidents due to level $i$ of factor $\boldsymbol{A} ; \beta_{j}=$ the effect on the expected number of accidents due to level $j$ of factor $\boldsymbol{B} ;(v \beta)_{i j}=$ the extra effect on the expected number of accidents due to levels $i$ and $j$ of factors $\boldsymbol{A}$ and $\boldsymbol{B}$ respectively and $\xi_{i j t}=$ the data error.

Therefore, in this kind of model it can be assumed that each factor has two levels. Factor $\boldsymbol{A}$ has levels $i=1=$ treatment group and $i=2=$ comparison group. Factor $B$ has levels $j=1=$ "before" period and $j=2=$ "after" period. Therefore, $\psi_{i j t}$ can be modelled by totalling the effects of factor $\boldsymbol{A}$, factor $\boldsymbol{B}$ and the effects of the interaction between both factors $(v \beta)_{i j}$. Safety impact $S /(\%)$ is considered null when $v \beta_{i j}$ is not significant. Consequently, it is very important to clarify whether $v \beta_{i j}$ is significant or not. In keeping with this, the strategy to follow has been developed in the following two steps:

1. In order to check if $v \beta_{i j}$ is significant, test its effect on the two-factor factorial model.

2. If $v \beta_{i j}$ proves to be significant, use another scheme with independent levels. This scheme will be carried out in order to confirm if the engineering treatment has a positive (or negative) $S /(\%)$. 


\subsubsection{Determining whether the interaction effect is significant}

The case where $v \beta_{i j}$ is not significant is shown in figure 1a. The "before" and "after" periods are represented on the $\mathrm{x}$-axis and $\bar{\psi}_{i j}$. on the y-axis. There are two straight lines- the broken line is the treatment group and the continuous line is the comparison group. The two straight parallel lines have the same temporal variation. This means that $S I(\%)$ is equal to zero. Nonetheless, in figure $1 \mathbf{b}$ there is enough evidence to indicate that the interaction effect might be important. The two straight lines are not parallel and therefore do not have the same temporal variation, -a fact which results in a $S /(\%)$ which could be positive or negative. Even so, it is still not certain that $v \beta_{i j}$ is significant. It would be necessary to verify whether or not $v \beta_{i j}$ is significant. For this purpose, the following hypothesis testing is used (Vilar, 2001; (Sahai and Ageel, 2000)):

$$
\left\{\begin{array}{l}
H_{0}^{A B}=(v \beta)_{11}-(v \beta)_{12}-(v \beta)_{21}+(v \beta)_{22}=0 \\
H_{1}^{A B}=(v \beta)_{11}-(v \beta)_{12}-(v \beta)_{21}+(v \beta)_{22} \neq 0
\end{array}\right\}
$$

where $H_{0}^{A B}=$ Null hypothesis, i.e., $v \beta_{i j}$ is zero. $H_{1}^{A B}=$ Alternative hypothesis, i.e., $v \beta_{i j}$ is different from zero. $v \beta_{i j}=$ Interaction effect: in the treatment group $(i=1)$, in the comparison group $(i=2)$; in the "before" period $(j=1)$, in the "after" period $(j=2)$. Moreover, to implement this test equal sample sizes are used: $n_{i j}=r=$ Number of locations for each one of the crossed levels of the factors. The previous hypothesis testing is resolved making use of the variance analysis technique. In particular, the null hypothesis $H_{0}^{A B}$ should be rejected when (Vilar, 2001):

$$
\hat{F}=(\text { ABss } / R s s)>F_{1,4(r-1), \alpha}
$$

where $\alpha$ is taken as equal to 0.05 for Fisher's $\boldsymbol{F}$ distribution with a degree of freedom in the numerator and $4(r-1)$ degrees of freedom in the denominator. Rss is the Residual sum of the squares with the twofactor factorial model and may be calculated by:

$$
R s S=(1 / 4 r-4) \sum_{i=1}^{2} \sum_{j=1}^{2} \sum_{t=1}^{r}\left(\psi_{i j t}-\psi_{i j .}\right)^{2}
$$

and, $A B s s$ is the Sum of the squares for the interaction: 


$$
\text { ABss }=\sum_{i=1}^{2} \sum_{j=1}^{2} r\left(\Psi_{i j .}-\Psi_{i . .}-\Psi_{. j .}+\Psi_{. . .}\right)^{2}
$$

where $\bar{\psi}_{i . .}=$ Averages of the expected numbers of accidents for level $i$ of factor $\boldsymbol{A}$. There are two averages: level $i=1$ (in the treatment group, "before" and "after" periods); and level $i=2$ (in the comparison group, "before" and "after" periods). $\bar{\psi}_{. j .}=$ Averages of the expected numbers of accidents for level $j$ of factor $\boldsymbol{B}$. There are two averages: level $j=1$ (in the "before" period, treatment group and comparison group); and level $j=2$ (in the "after" period, treatment group and comparison group). $\bar{\psi}_{\ldots}=$ Overall average of the expected numbers of accidents for the all levels (in this case four levels).

\subsubsection{Determining whether a positive or negative safety impact exists}

When $v \beta_{i j}$ is significant $S /(\%)$ would never be equal to zero, having either to adopt a positive value or a negative one. To confirm the latter, it is preferable to refer to the diagram presented in figure 1c, in which four independent levels offer all the combinations of factors. The so-called "single-factor model" (Sahai and Ageel, 2000) is proposed for use:

$$
\psi_{i j t}=\mu+\tau_{1}+\tau_{2}+\tau_{3}+\tau_{4}+\xi_{i t}
$$

where $\mu=$ constant; $\tau_{1}=$ effect on the expected number of accidents due to level $i=1$ (in the treatment group and "before" period); $\tau_{2}=$ effect on the expected number of accidents due to level $i=2$ (in the treatment group and "after" period); $\tau_{3}=$ effect on the expected number of accidents due to level $i=3$ (in the comparison group and "before" period); $\tau_{4}=$ effect on the expected number of accidents due to level $i=4$ (in the comparison group and "after" period) and $\xi_{i t}=$ the data error.

In this kind of model, to confirm if $S /(\%)$ has a significant positive (or negative) value the following hypothesis testing is used (Vilar, 2001):

$$
\left\{\begin{array}{l}
H_{0}: \sum_{i=1}^{4} b_{i} \tau_{i}=0 \\
H_{1}: \sum_{i=1}^{4} b_{i} \tau_{i} \neq 0
\end{array}\right\}
$$


where $H_{0}=$ Null hypothesis, i.e., it has a significant positive (or negative) value and $H_{1}=$ Alternative hypothesis, i.e., it has not a significant positive (or negative) value with $b_{i}=$ Coefficients which fulfil $\sum_{i}^{4} b_{i}=0$ and $\tau_{i}=$ Effect on the expected number of accidents due to level $i$.

On this occasion, $H_{0}$ is rejected when it fulfils the determining rule (Vilar, 2001):

$$
\hat{t}=\left|\left(\sum_{i=1}^{4} b_{i} \psi_{i .}\right) / \sqrt{m R s s \sum_{i=1}^{4} \frac{b_{i}^{2}}{r}}\right|>t_{(4 r-4), \alpha / 2}
$$

where $\alpha$ is equal to 0.05 for Student's $\boldsymbol{t}$ distribution with (4r-4) degrees of freedom. The Mean residual sum of the squares (mRss) is calculated by:

$$
m R s s=\sum_{i=1}^{4} \sum_{t=1}^{r}\left(\psi_{i t}-\psi_{i .}\right)^{2} /(4 r-4)
$$

where $\psi_{i t}=$ Expected number of accidents in level $i$, at location $t . \bar{\psi}_{i}=$ Averages of $\psi_{i t}$ on each level $i$. In Figure 1c, point 2 is taken as a reference to determine where $\bar{\psi}_{i}$. is situated. In this way the following hypotheses are tested (Vilar, 2001):

$$
\begin{array}{ll}
H_{0}^{1}: & -1 \tau_{1}+1 \tau_{2}+0 \tau_{3}+0 \tau_{4}=0 \\
H_{0}^{2}: & 0 \tau_{1}+1 \tau_{2}-1 \tau_{3}+0 \tau_{4}=0 \\
H_{0}^{3}: & 0 \tau_{1}+1 \tau_{2}+0 \tau_{3}-1 \tau_{4}=0
\end{array}
$$

$H_{0}^{1}$ situates point 1 ("before" period in the treatment group) in relation to point 2 ("after" period in the treatment group). If the result of the test is negative and significant, point 1 is above point 2. $H_{0}^{2}$ situates point 3 ("before" period in the comparison group) in relation to point 2. If the result of the test is negative and significant, point 3 is above point 2. $H_{0}^{3}$ situates point 4 ("after" period in the comparison group) in relation to point 2. If the result of the test is negative and significant, point 4 is situated above point 2. Finally, bear in mind that each of the three previous tests is considered statistically significant when the estimator of Student's $\boldsymbol{t}$ fulfils the determining rule (equation 10). Depending on the relative position of the previously described points, it is possible to confirm if $S /(\%)$ is positive (or negative). 


\section{Categorisation}

\subsection{Data base}

In order to categorise the roads, data must be compiled on road infrastructure, traffic accidents with fatalities and injuries and the Annual Average Daily Traffic Volume (AADT). The data on the engineering treatments, traffic volumes and road infrastructure were provided by the ACM's Highway Department. Accident data were obtained from the central computerised files of the National Traffic Control Department (DGT). A database was created for sections of rural roads in the ACM, based on the Highway Planning information available from 1986-1993 (Autonomous Community of Madrid, 1994). The ACM's Highway Network was divided into sections that were as uniform as possible so that they would share physical, geometric and traffic characteristics. These sections were always the same length- one kilometre.

\subsection{Variance Analysis}

A classification was made to carry out a variance analysis in order to reduce the variability of the highway network from the standpoint of the number of accidents so that the reference groups would be as homogeneous as possible. The number of kilometres of rural roads was 2457 . There were only 120 kilometres of divided roads which were expressways. The remaining ones were undivided roads with two lanes: 1098 sections having an AADT $<1000$ and 1239 sections having an AADT $\geq 1000$. A significant difference in the number of accidents was found at the $95 \%$ confidence level.

Due to the scarcity and poor quality of the information, the data available for undivided roads having an AADT $<1000$ were omitted. To carry out this evaluation in the category pertaining to undivided rural roads

with an AADT $\geq 1000$, the following information was culled from the data base: 75 highway upgrading projects $(346.32 \mathrm{~km}), 6$ traffic signing treatments $(38.30 \mathrm{~km}), 26$ pavement marking treatments $(152.45 \mathrm{~km})$ and 75 pavement resurfacings $(298.27 \mathrm{~km})$.

\section{Evaluation process}

\subsection{Selection of locations}

Engineering treatments were performed over a period of time ranging from 1986 until 1993. Logically, over such a long period of time, a temporary trend of accidents was found in ACM's Highway Network. For the 
purpose of solving this serious stumbling block, it was decided to use the sections implemented between the years 1986 and 1989 as the treated group and the sections implemented between the years 1990 and 1993 as the comparison group (figure 2). In this sense, the selected locations for the evaluation were the following (table 1):

- Highway upgrading. A random selection was made of 50 sections for the treatment group and 50 sections for the comparison group.

- Traffic signing. 15 sections were taken directly for the treatment group and 15 sections for the comparison group.

- Pavement markings. A random selection was made of 50 sections for the treatment group and 50 sections for the comparison group.

- Pavement resurfacings. A random selection was made of 50 sections for the treatment group and 50 sections for the comparison group. Also taken were 20 sections where at least one accident by skidding on wet surfacing had occurred during the preceding two-year period. Half of these sections were used as treated locations and half as comparison locations.

\subsection{Estimation of the expected number of accidents}

The well know Method of Moments (Al-Maseid, 1990) was used to fit the negative binomial distribution to the number of accidents $(N)$ over a period of one year in the whole reference group of similar sections belonging to ACM's Highway Network. In each "before" distribution period the fit was carried out exactly in the third year prior to the start date of the implementation of the treatment. In each 'after' distribution period the year subsequent to the finish date of the execution of the treatment was employed. The start and end date in each treated section were the same as the start and end date in each comparison section (Figure 2). Therefore, in both types of sections: $\alpha_{11 \mathrm{t}}=\alpha_{21 \mathrm{t}} ; \omega_{11 \mathrm{t}}=\omega_{21 \mathrm{t}} ; \alpha_{12 \mathrm{t}}=\alpha_{22 \mathrm{t}} ; \omega_{12 \mathrm{t}}=\omega_{22 \mathrm{t}}($ table 1), (figure 2).

Next, equation 1 was applied to estimate $\psi_{i j t}$. In each of the sections (treatment or comparison group), the number of recorded accidents $\left(N_{i j t}\right)$ during the "after" and "before" periods was extracted from the database comprising two years in duration $(y=2)$ (figure 2). It was assumed that $N_{i j t}$ was proportional to AADT. In this case it was observed that with relatively low traffic flows the assumption of direct proportionality is a 
reasonable approximation. So, if each location has its specific "before" and "after" AADT, the effect of a change in AADT may be accounted for separately at each location by applying a correction factor. This correction factor $C_{i 1 t}$ was equal to $Q_{i 2 t} / Q_{i 1 t}$; where $Q_{i 2 t}$ is the traffic flow in the "after" period and $Q_{i 1 t}$ in the 'before' period. Therefore, multiplying $N_{i 1 t}$ by $C_{i 1 t}$ the number of corrected accidents in the "before" period was obtained.

\subsection{Evaluation of the safety impact and significance test}

Once $\psi_{i j t}$ had been obtained for each of the sections, $\bar{\psi}_{i j}$. was calculated by applying equation 2 . Next, equation 3 was used to obtain the $S /(\%)$ of the engineering treatments. Finally the statistical significance of $S I / \%)$ was tested (equations 6 and 11$)$.

\section{Results}

\subsection{Highway Upgrading}

In the treatment group and comparison group, five a priori binomial negative distributions were fitted to the number of accidents $(N)$ in each "before" and "after" period (see parameters in table 1). A very good adjustment was found between the theoretical and actual frequency distributions in all the cases. For example, figure 3 reflects the specific case corresponding to the a priori parameters $\alpha_{\mathrm{i} 11}=0.9073$ and $\beta_{\mathrm{i} 11}=1.7829$. The sum of the number of expected accidents is shown in table 1. The averages of the number of expected accidents are given in table 2. From these results, the accidents "before" and "after" were compared in the treated and untreated sections, which resulted in a positive $S /(\%)$ of $32.77 \%$.

In figure 4 there appears to be an interaction between the two straight lines. However, to verify its actual significance, Fisher's $\boldsymbol{F}$ test was carried out. The calculations resulted in a value of $A B s s$ equal to 0.2748 and Rss equal to 0.0227 . The estimator $\hat{F}$ was equal to 12.0837 (Pvalue $=0.0006$ ). The latter value was above the critical value $F_{(1,196), 0.05}$. For this reason the null hypothesis that the two straight lines are parallel was rejected. Therefore the interaction effect is significant, although it has not yet been confirmed whether it has a positive influence. Student's $t$ test was performed to determine this. In this case, the value of $m R s s$ was equal to 0.0227 . Table 2 also presents the average values of the expected accidents $\left(\bar{\psi}_{i .}\right)$ in the case of 
independent levels. Furthermore, figure 4 shows the layout that was verified by means of hypotheses $\mathbf{1 3}, \mathbf{1 4}$ and 15. In this sense, the results were the following:

- On verifying the hypothesis of equation 13 the resulting estimator $\hat{t}_{1}$ was equal to -5.9016 (Pvalue $=0.0000)$ (table 2), a larger negative value in absolute value than $t_{(196), \alpha / 2}$. This means that point 1 is situated above point 2 .

- On verifying the hypothesis of equation 14 the resulting estimator $\hat{t}_{2}$ was equal to -3.7821 (Pvalue $=0.0002)$, a larger negative value in absolute value than $t_{(196), \alpha / 2}$. which means that point 3 is situated above point 2. Point 3 is situated under point 1.

- On verifying the hypothesis of equation 15 the estimator $\hat{t}_{3}$ was equal to -2.7966 (Pvalue $=0.0057$ ), a larger negative value in absolute value than $t_{(196), \alpha / 2}$. This means that point 4 is situated above point 2 , point 4 is situated under point 3 and point 1.

Furthermore, the magnitude of the values of the estimators give us an idea of how far points 1, 3 and 4 are with respect to point 2. These results confirm figure 4 where it is clear that point 1 is the furthest away from 2 , followed by point 3 . Point 4 is the closest. Consequently, it may be definitely confirmed that the two straight lines are not parallel and that the $S /(\%)$ is significant and positive.

\subsection{Traffic Signing}

There were two a priori distributions fitted in each "before" and "after" period (table 1). A good adjustment was found between theoretical and actual frequency distributions. A positive $S /(\%)$ of $10.73 \%$ was obtained (table 2). The value of $A B s s$ was equal to 0.0045 and that of Rss 0.0197 , giving rise to an estimator $\hat{F}$ equal to 0.2307 (Pvalue $=0.6329)$. The latter value is smaller than the critical $F_{(1,56), 0.05}$. Therefore, the null hypothesis that the straight lines in figure $\mathbf{5}$ are parallel was not rejected. The traffic signing treatments did not have a significant $S /(\%)$.

\subsection{Pavement Markings}

There were five a priori distributions fitted in each "before" and "after" period (table 1). A good fit was found between theoretical and actual distributions. A positive $S /(\%)$ of $13.63 \%$ was obtained. The value of $A B s S$ was equal to 0.0171 and $R s s$ to 0.0102 , giving rise to an estimator $\hat{F}$ equal to 1.6489 (Pvalue $=0.1958$ ). The latter value is smaller than the critical $F_{(1,196), 0.05}$. The null hypothesis that the straight lines in figure 6 are 
parallel was not rejected. It may be confirmed that the repainting of pavement markings did not have a significant $S /(\%)$.

\subsection{Pavement Resurfacings}

\subsubsection{Sections with wet-weather and dry-weather accidents}

There were five a priori distributions fitted in each "before" and "after" period (table 1). A good fit was found between theoretical and actual distributions. A negative $S /(\%)$ of $-2.12 \%$ was obtained (table 2 ).

In figure 7a accidents were observed to increase in the "after" periods in both the treated group and the comparison group. This would imply, in any case, that even though pavement resurfacings were not being carried out, in these sections the average expected number of accidents would have increased. But it is necessary to determine whether there is a significant difference between the increase in accidents in both groups.

In this sense, Fisher's $\boldsymbol{F}$ test was carried out to check and see if the interaction effect is null in figure $7 \mathrm{a}$. The values of $A B s s$ and of Rss were 0.0005 and 0.0156 respectively; which gave rise to an estimator $\hat{F}$ equal to 0.0310 (Pvalue $=0.8604)$. The latter value is smaller than the critical one obtained for $F_{(1,196), 0.05}$. Therefore, the null hypothesis was not rejected. This means that $S /(\%)$ is not significant.

\subsubsection{Sections with wet-weather accidents}

There were three a priori distributions fitted in each "before" and "after" period (table 1). A good fit was found between theoretical and actual distributions. In this case, a positive $S /(\%)$ of $36.37 \%$ was obtained (table 2, figure 7a). The values of $A B s s$ and Rss were 0.0188 and 0.0559 respectively. The estimator $\hat{F}$ was equal to 0.3365 (Pvalue $=0.5655$ ). The latter value is smaller than the critical one obtained with $F_{(1,36), 0.05}$. Consequently, the null hypothesis was not rejected. This means that $S /(\%)$ is not significant.

\section{Discussion of results}

The safety impact of highway upgrading yielded a positive and significant value of $33 \%$. However, this was not conceived within a mass program oriented towards the elimination of accidents. In spite of the fact that there were problems of safety on many sections of road, the treatments were directed preferably towards improving the level of service by means of updating design standards. As a consequence, when the surface 
and geometric characteristics are improved at the same time, together with other improvements in signing, it is logical that a positive safety impact as a whole would be obtained in the sections where there had been problems with road safety. In this sense, the safety impact is within the range of 21 to $90 \%$ obtained in the U.S.A. when carrying out the RRR projects evaluation (Transportation Research Board, 1987; Cleveland, 1987).

The evaluations of the safety impact of traffic signing (11\%) and of pavement markings (14\%) have been positive but non-significant. Here, neither the improvement in traffic signing nor the repainting of road markings were in response to a programme carried out en masse with the intention of eliminating black spots. Nonetheless, it is reasonable that they have had a positive impact, since they have as their main objective an increase in traffic safety, efficiency and convenience. Therefore, the impacts of both treatments are in agreement with other studies carried out previously by the FHWA and the TRL (Al-Masaeid, 1994; Llamas, 1998).

In general this article has corroborated the results based on different analytical tools (Vogt and Baret, 1998; Thighe et al, 2000; Zhang and Ivan, 2005. They all confirm that the distinct elements of a highway's geometric design are factors that can be controlled by civil engineers. For this reason, a good geometric design as well as good traffic signing and road marking provide drivers with travelling conditions and information that will allow them to spot and evaluate conflicts. They can therefore make the best decisions to avoid possible dangers and, in turn, overall road safety is improved.

On the other hand, in this study, when dry and wet-weather accidents were computed, the safety impact of pavement resurfacings yielded a negative and non-significant value of $-2 \%$. On the contrary, when only accidents by skidding on wet surfacing were computed, the impact resulted in a positive and non-significant value of $36 \%$. These numbers are in keeping with the results obtained in other studies carried out previously (Cleveland, 1987).

The safety impact of pavement resurfacing treatments is a controversial topic. Some authors claim that this treatment improves road safety; others hold the opposite opinion. According to one group of researchers, the influence of pavement resurfacings on safety is akin to a double-edged sword. Once irregularities in the old road surface have been eliminated, driving conditions improve. In turn, drivers augment their speed and the 
risk of accidents also increases. Another general effect of this measure is that the surface becomes more resistant to skidding, leading to reduced braking distances. Thus, vehicle handling in wet surface conditions improves. One would expect that these would also lower the risk of accidents (Transportation Research Board, 1987; Cleveland, 1987).

In this case, pavement resurfacings were carried out mainly with the aim of improving the structural performance of the pavement. These resurfacings were done on complete sections of highways and were not implemented on curves or intersections, where treatments - of short lengths - are generally carried out to improve resistance to skidding. That is to say, these treatments were not, at any time, in response to a need to implement a programme en masse for the elimination of accidents recorded on wet surfacing. Proof of this is that the wearing course was not realised with bituminous mixtures especially designed against the skidding of vehicles, rather it was implemented with hot bituminous mixtures of dense or close grading. Moreover, they did not coincide with any other geometric improvement. It is therefore possible that when previous geometric conditions are good, pavement resurfacings are beneficial to road safety, for the reasons mentioned above. If, on the other hand, previous geometric conditions are unsatisfactory, these measures might go against safety. Drivers, unaware of real risks, exceed the recommended speed and may cause accidents.

\section{Conclusions}

The conclusions obtained on undivided rural roads of ACM's Highway Network may be summarised as follows:

- When highway upgrading was carried out, the safety impact of these engineering treatments was 33\%, this being a significant value. Therefore, highway upgrading had a positive and significant safety impact.

- When a programme of RRR projects planned to update design standards was carried out, it led to an improvement in road traffic safety. Consequently, the combination of the effect of the pavement's structural rehabilitation with the effect of other improvements (horizontal and vertical alignments, lateral characteristics of the highway, road markings, traffic signs) had a positive and significant safety impact.

- The safety impact of the updating and improvement of traffic signing was $11 \%$, which was a nonsignificant value. Therefore, the updating and improvement of horizontal signing had a positive but nonsignificant effect on road safety. 
- The safety impact of the repainting of pavement markings in a bad state of maintenance was $14 \%$, This value is non-significant. Therefore, the repainting of road markings had a positive but non-significant impact on road safety.

- The safety impact of pavement resurfacings on sections with dry and wet-weather accidents was $-2 \%$ and on sections with wet-weather accidents, $36 \%$. These values are non-significant.

- When a programme of pavement resurfacings, not motivated by accident prevention, is implemented for the sole purpose of the structural rehabilitation of the pavement, an improvement in road safety is not produced.

This work has shed light on the difficulty in evaluating the safety impact of engineering treatments that have been carried out over an extended period of time. This makes it difficult to control the effect produced by the temporary tendency towards the occurrence of accidents throughout the above-mentioned period. Even so, in this article a procedure has been employed where, by means of using comparison locations in stages, it has been possible to evaluate the safety impact of engineering treatments.

Also, this article has confirmed the implementation of a simple procedure to test the significance of the safety impact of improvement treatments based on the principles of experimental design.

Finally, it must be said that there is a need to develop an evaluation method that will allow the safety impact of road treatments to be estimated, in the absence of which the use of comparison locations has been necessary.

\section{References}

- ABBESS, C. ET AL., 1981. Accidents at black spots: estimating the effectiveness of remedial treatment, with special reference to the regression-to-mean effect. Traffic Engineering and Control. Vol. 22, no. 10, 535-542.

- AL-MASAEID, H. R., 1990. Bayesian Approach to the Estimation of Expected Number of Accidents. A Thesis Submitted to the Faculty of Pardue University in Partial Fulfilment of the Requirements for the Degree of Doctor of Philosophy.

- AL-MASAEID, H. R. and SINHA, K. C., 1994. Analysis of Accident Reductions Potentials of Pavement Markings. Journal of Transportation Engineering, Vol. 120, $\mathrm{n}^{\circ}$ 5, 723-737.

- CLEVELAND, D. E., 1987. Effect of Resurfacing on Highway Safety. Relation between Safety and Key Highway Features. State of the Art Report 6, Transportation Research Board, Washington, DC.

- COMUNIDAD DE MADRID, 1994. Plan de Carreteras 1994-2001. Consejería de Transportes, Dirección General de Carreteras. España.

- COUNCIL, F. L. ET AL., 1980. Accident Research Manual. National Highway Traffic Safety Administration, Washington, DC. 
- HAUER, E., 1997. Observational Before-After Studies in Road Safety. Estimating the effect of highway and traffic engineering measures on road safety. Pergamon.

- LEOTSARAKOS, C., 1988. A comparative Statistical Analysis of Traffic Accidents in Highway construction Zones. Dissertation presented in Partial Fulfilment of the Requirements for the Degree Doctor of Philosophy in the Graduate School of the Ohio State University.

- LlAMAS RUBIO, D. R., 1998. Eficacia y Rentabilidad de las Medidas de Bajo Coste. In: IV Jornadas de Seguridad Vial. Santander, España, pp. 331-346.

- MARITZ, J. S., and LWIN, T., 1989. Empirical Bayes Methods. Second Edition, Chapman y Hall.

- SAHAI, H., AGEEL, M. I., 2000. The Analysis of Variance. Fixed, Random and Mixed Models. Birkhäuser. Berlin.

- $\quad$ TIGHE, S., and LI, N., COWE, L., and HAAS, R. (2000). Incorporating Road Safety into Pavement Management. Transportation Research Record 1699. TRB. National Research Council. Washington, D.C.

- TRANSPORTATION RESEARCH BOARD, 1987. Special Report 214. Designing Safer Roads. Practices for Resurfacing Restoration, and Rehabilitation. National Research Council. Washington, D. C.

- VILAR FERNÁNDEZ, J. A., 2001. Diseño y análisis de experimentos. Curso de postgrado en estadística aplicada. Universidade da Coruña, Spain.

- VOGHT. A and BARET, J (1998). Accident Models for Two-lane rural Segments and Intersections. Transportation Research Record 1635. National Research Council, Washington, D.C.

- ZHANG, C., and IVAN, J. (2005). Effects of Geometric Characteristics on Head-on Crash Incidence on Two-Lane Roads in Connecticut. Transportation Research Board $84^{\text {th }}$ Annual Meeting, January 2005. CD ROM. 
Table 1. A priori distribution parameters and total number of accidents expected

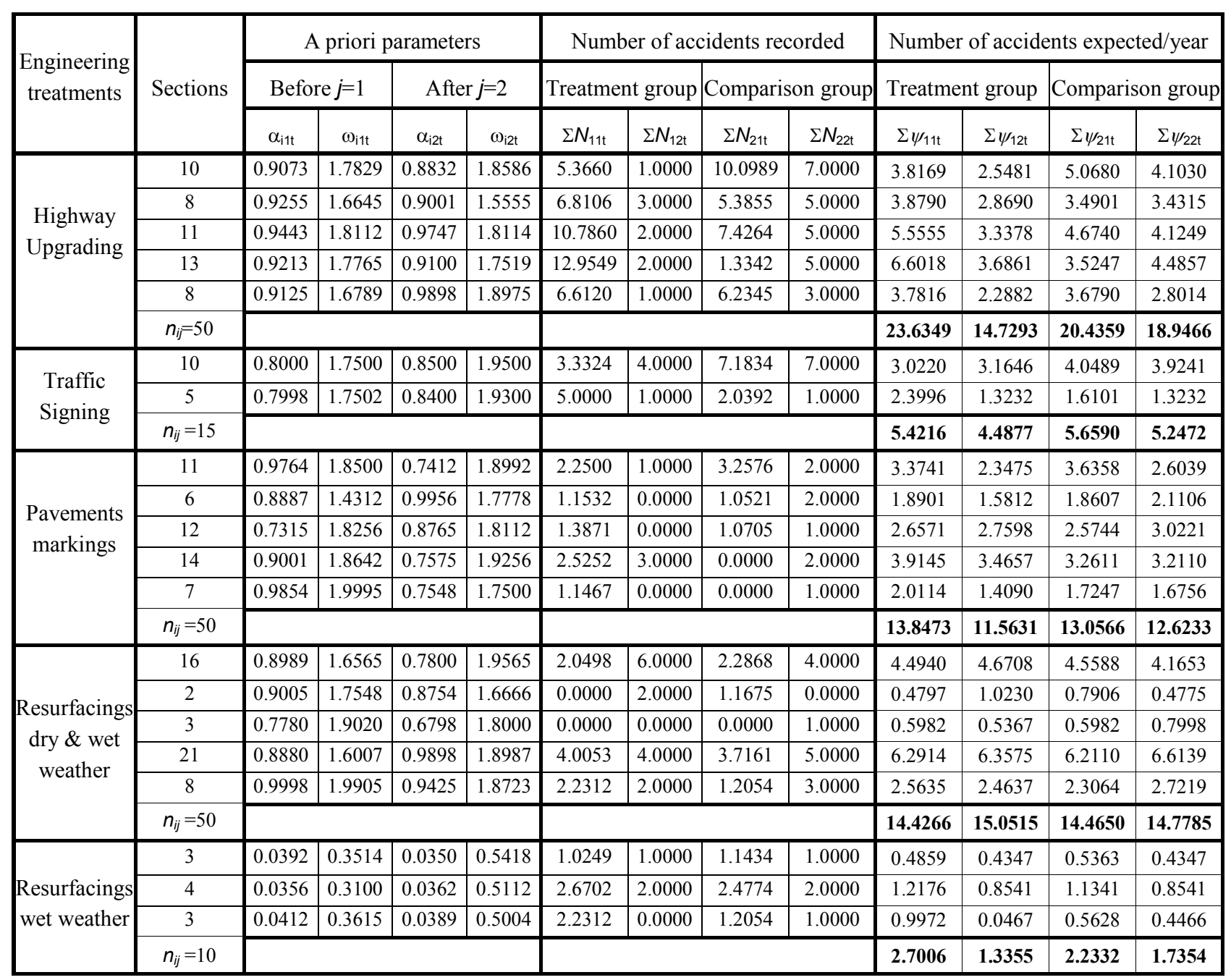


Table 2. Safety impacts of engineering treatments

\begin{tabular}{|c|c|c|c|c|c|c|}
\hline \multirow{2}{*}{\multicolumn{2}{|c|}{ Indicator }} & \multirow{2}{*}{$\begin{array}{l}\text { Highway } \\
\text { Upgrading }\end{array}$} & \multirow{2}{*}{$\begin{array}{l}\text { Traffic } \\
\text { Signing }\end{array}$} & \multirow{2}{*}{$\begin{array}{l}\text { Pavement } \\
\text { Markings }\end{array}$} & \multicolumn{2}{|c|}{ Pavement Resurfacings } \\
\hline & & & & & $\begin{array}{c}\text { Dry \& wet-weather } \\
\text { accidents }\end{array}$ & $\begin{array}{c}\text { Wet-weather } \\
\text { accidents }\end{array}$ \\
\hline $\bar{\psi}_{11 .}$ & $\bar{\psi}_{1}$ & 0.4726 & 0.3614 & 0.2769 & 0.2885 & 0.2701 \\
\hline $\bar{\psi}_{12}$ & $\bar{\psi}_{2}$ & 0.2946 & 0.2992 & 0.2313 & 0.3010 & 0.1335 \\
\hline $\bar{\psi}_{21}$ & $\bar{\psi}_{3}$ & 0.4087 & 0.3773 & 0.2611 & 0.2893 & 0.2233 \\
\hline $\bar{\psi}_{22}$ & $\bar{\psi}_{4}$ & 0.3789 & 0.3498 & 0.2525 & 0.2956 & 0.1735 \\
\hline \multicolumn{2}{|c|}{$S I(\%)$} & 32.77 & 10.73 & 13.63 & -2.12 & 36.37 \\
\hline \multicolumn{2}{|c|}{$n_{i j}$} & 50 & 15 & 50 & 50 & 10 \\
\hline \multicolumn{2}{|c|}{$\hat{F}$ (Pvalue) } & $12.0837(0.0006)$ & $0.2307(0.6329)$ & $1.6489(0.1958)$ & $0.0310(0.8604)$ & $0.3365(0.5655)$ \\
\hline \multicolumn{2}{|c|}{$\hat{t}_{1}$ (Pvalue) } & $-5.9016(0.0000)$ & ---- & ---- & ---- & ---- \\
\hline \multicolumn{2}{|c|}{$\hat{t}_{2}$ (Pvalue) } & $-3.7821(0.0002)$ & --- & --- & --- & --- \\
\hline \multicolumn{2}{|c|}{$\hat{t}_{3}$ (Pvalue) } & $-2.7966(0.0057)$ & ---- & ---- & ---- & ---- \\
\hline \multicolumn{2}{|c|}{ Significant } & YES & NO & NO & NO & NO \\
\hline
\end{tabular}


a. Non-significant interaction

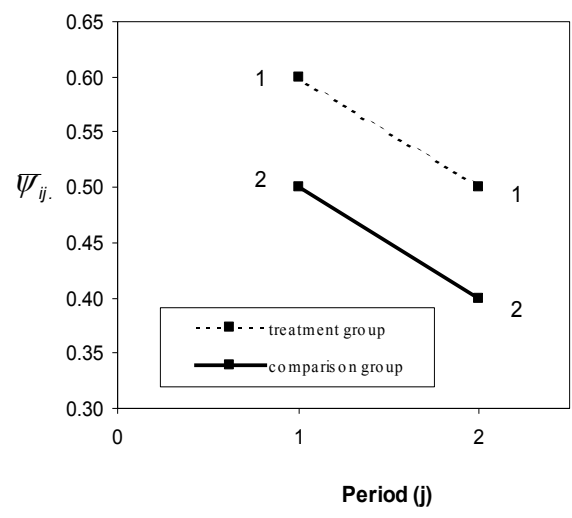

b. Significant interaction

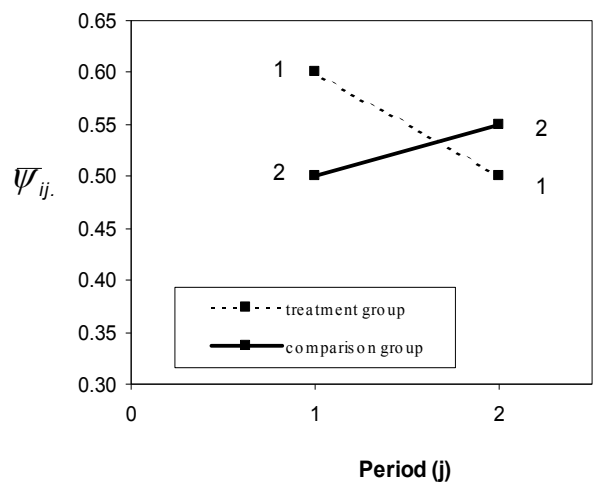

c. Layout with four independent levels

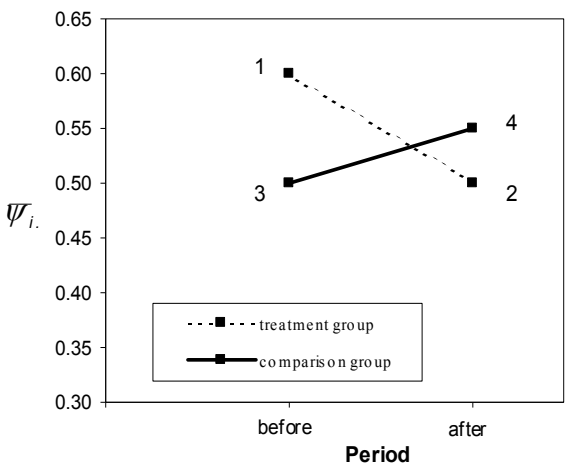

Figure 1. Examples 


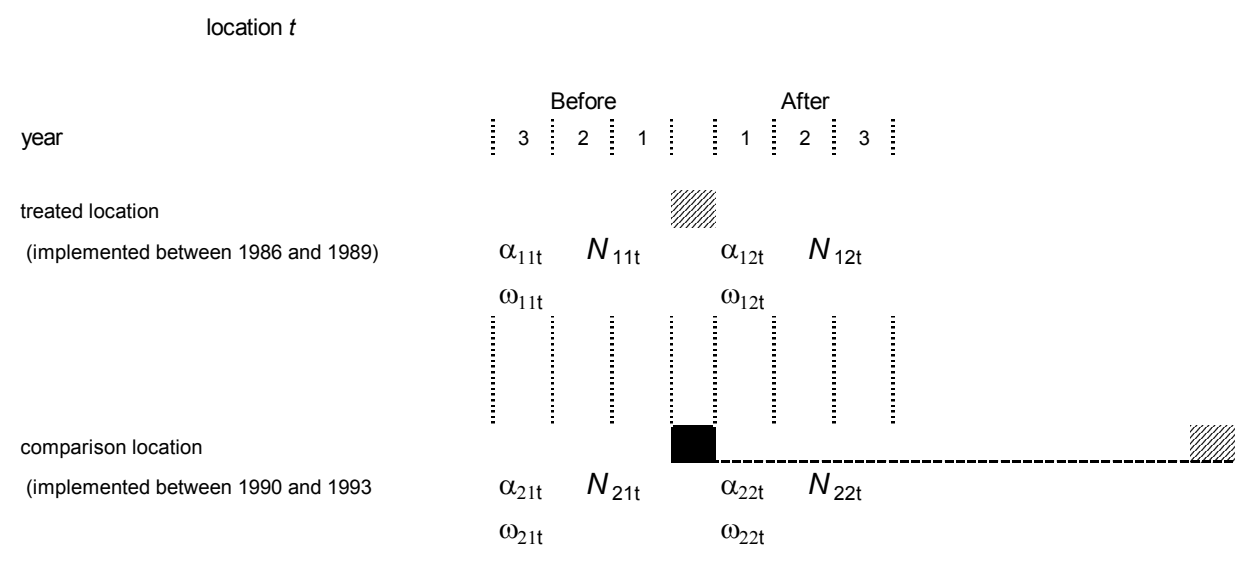

Figure 2. Periods for estimating a priori parameters and "before" and "after" periods in each location 


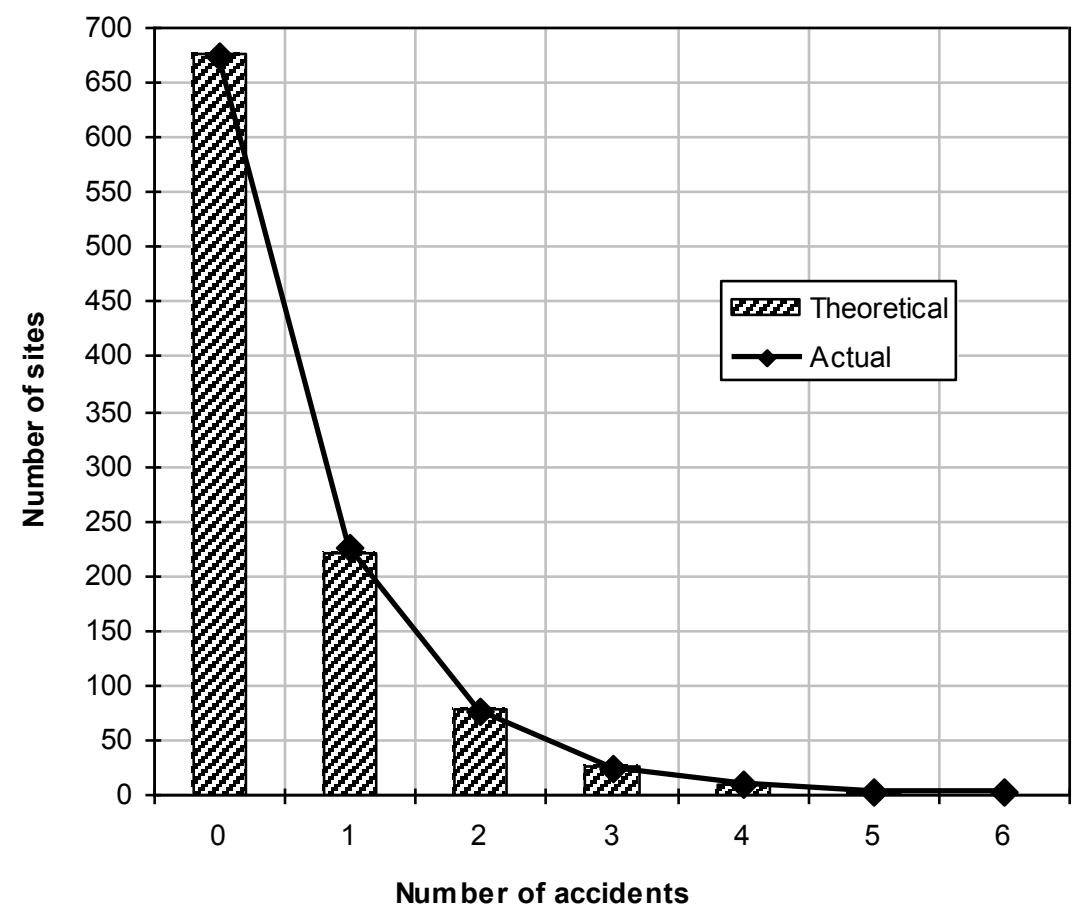

Figure 3. Actual and theoretical accident frequencies for Highway Upgrading

$\alpha_{i 1 t}=0.9073$ and $\beta_{i 1 t}=1.7829$ 


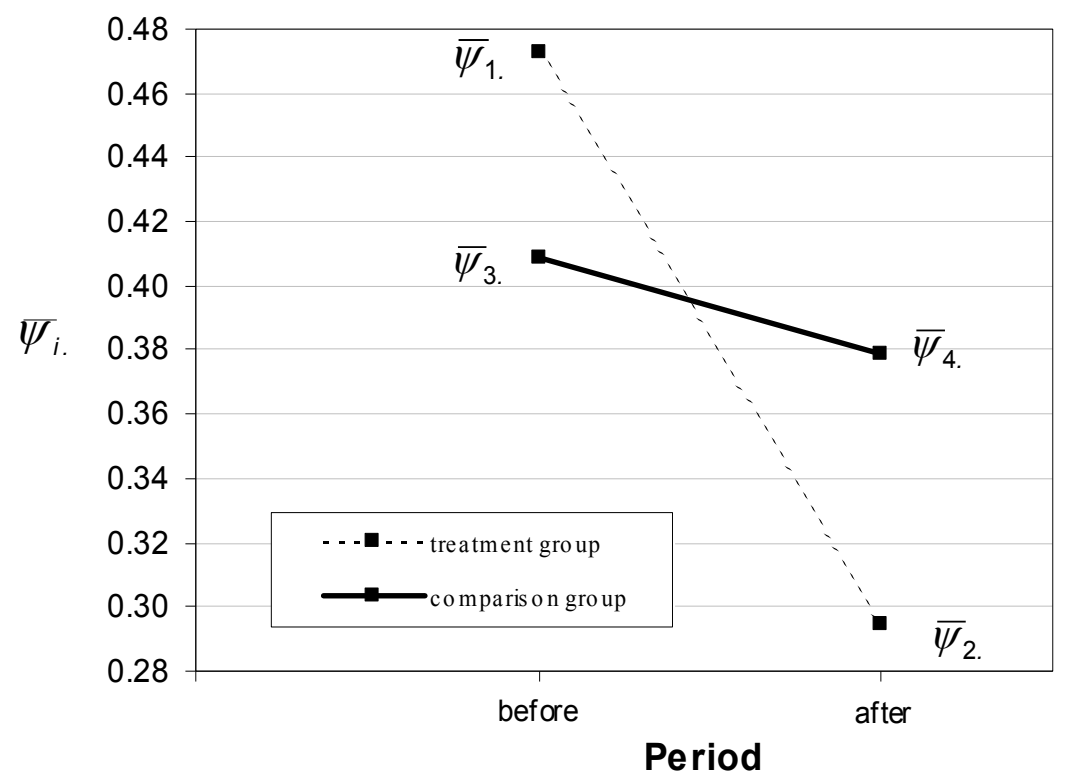

Figure 4. Highway Upgrading 


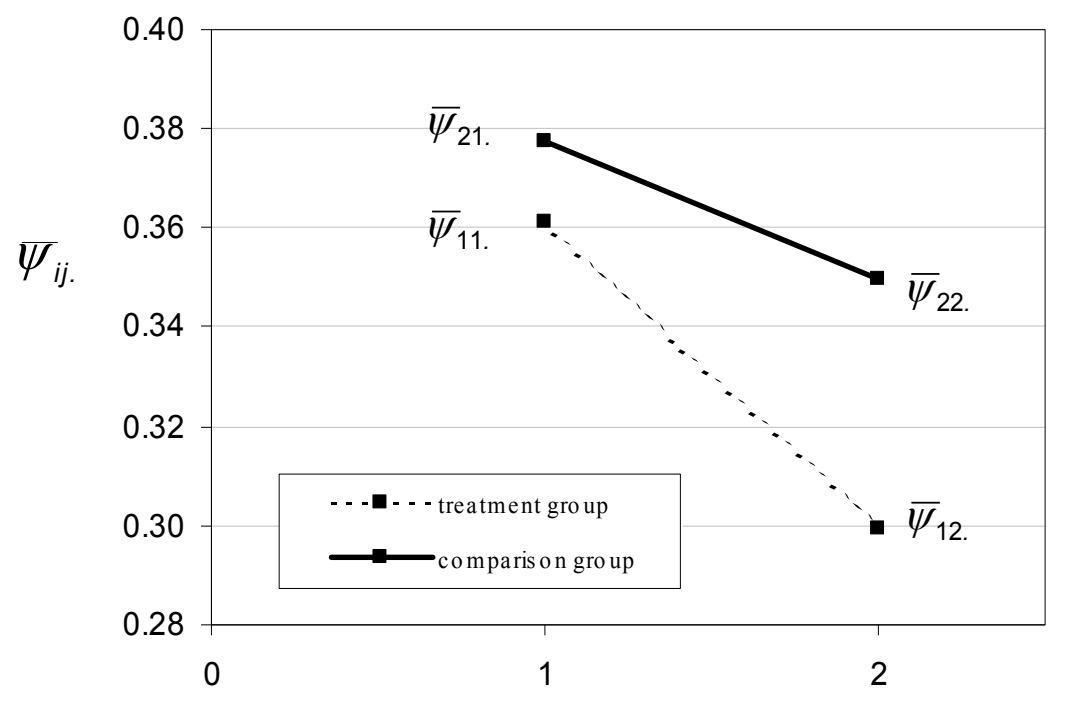

Period (j)

Figure 5. Traffic Signing 


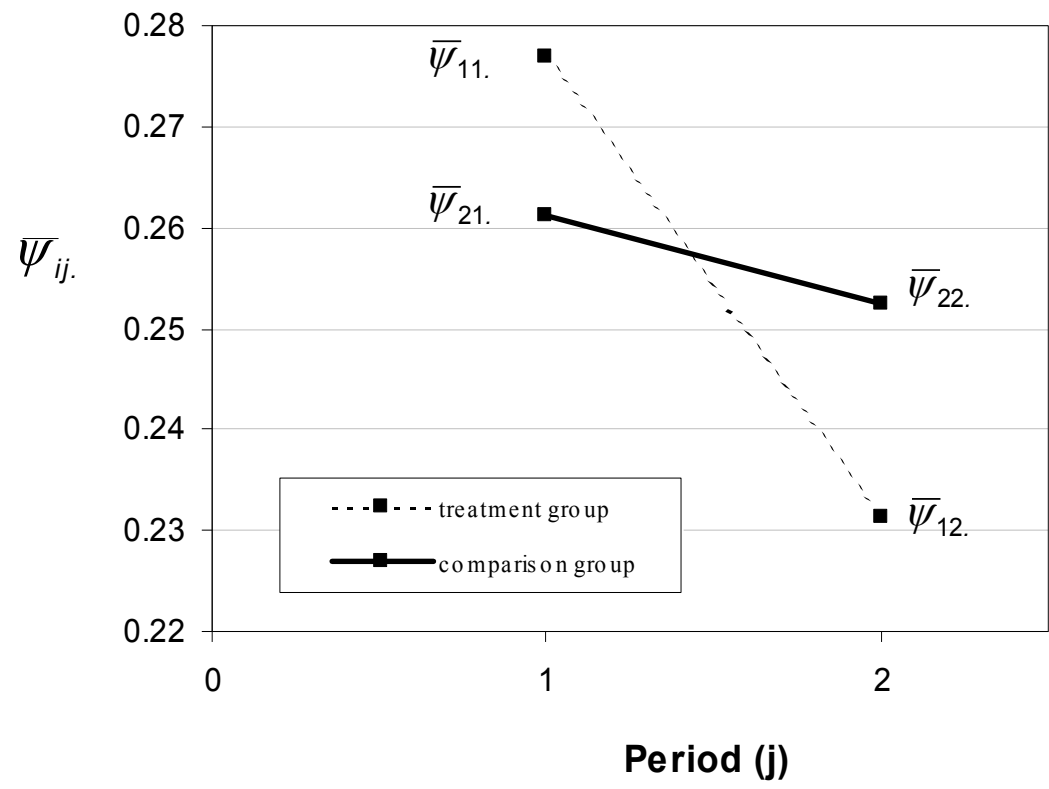

Figure 6. Pavement Markings 
a. Dry and wet weather

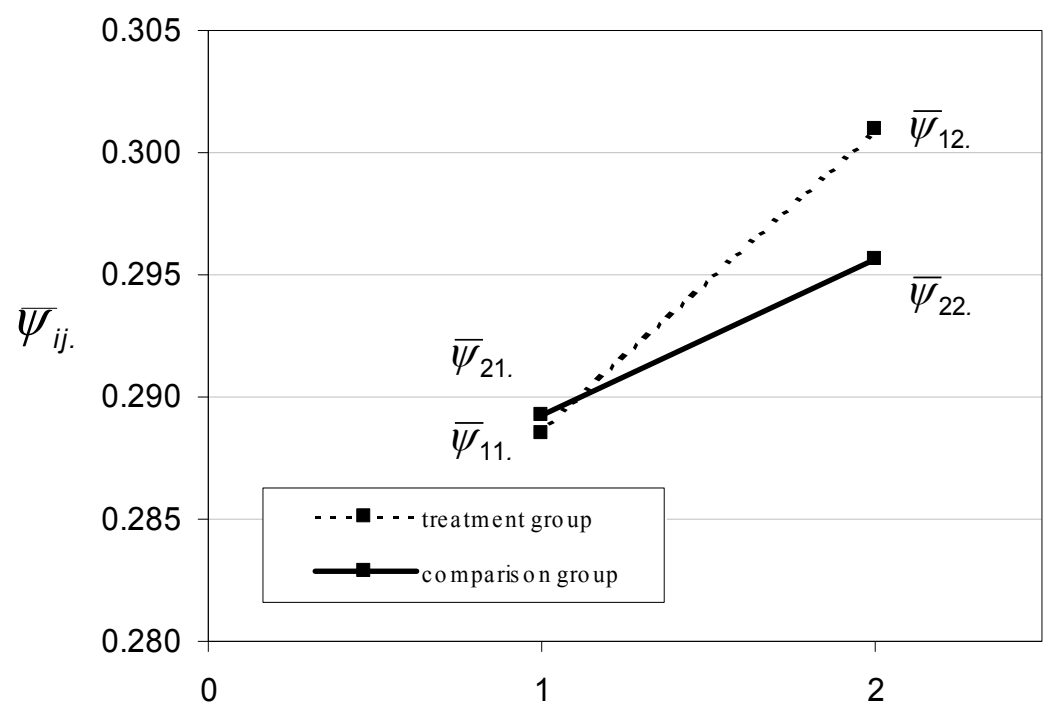

Period (j)

b. Wet weather

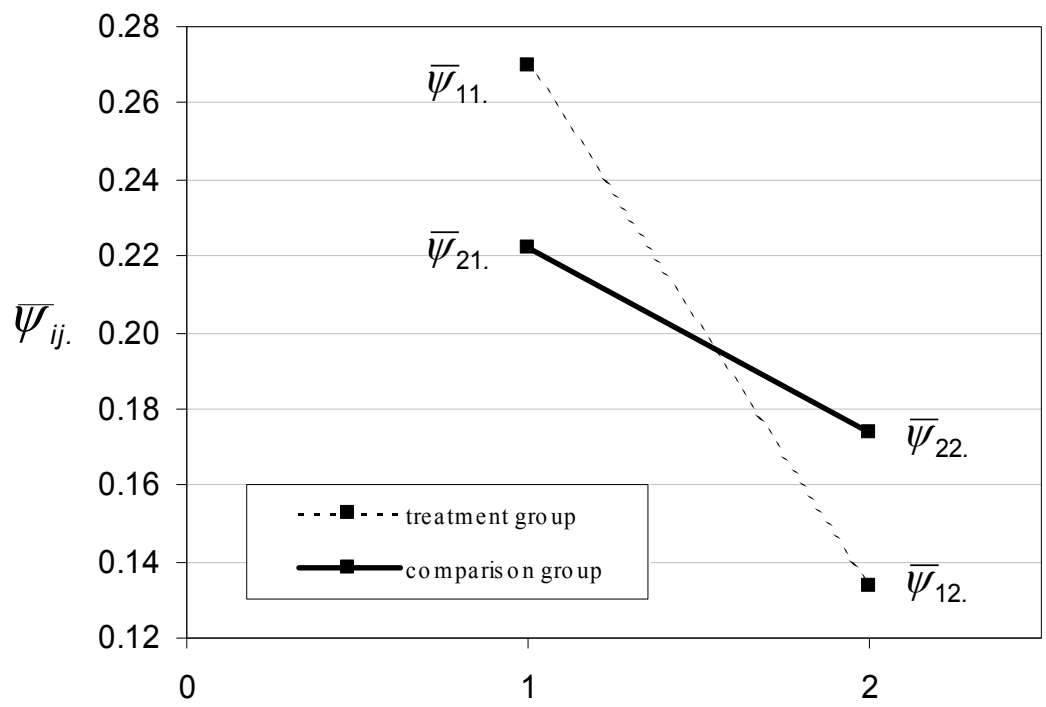

Period (j)

Figure 7. Pavement Resurfacings 